\title{
Raman Spectroscopy of Amorphous Carbon Prepared by Pulsed Arc Discharge in Various Gas Mixtures
}

\author{
M. Marton, ${ }^{1}$ M. Vojs, ${ }^{1}$ E. Zdravecká, ${ }^{2}$ M. Himmerlich, ${ }^{3}$ T. Haensel, ${ }^{3}$ S. Krischok, ${ }^{3}$ \\ M. Kotlár, ${ }^{1}$ P. Michniak, ${ }^{1}$ M. Veselý, ${ }^{1}$ and R. Redhammer ${ }^{1}$ \\ ${ }^{1}$ FEI, STU in Bratislava, Ilkovičova 3, 84104 Bratislava, Slovakia \\ ${ }^{2}$ Department of Technologies and Materials, FME TU of Košice, Mäsiarska 74, 04001 Košice, Slovakia \\ ${ }^{3}$ Center for Micro- and Nanotechnologies, TU Ilmenau, Gustav-Kirchhoff-Straße 7, 98693 Ilmenau, Germany \\ Correspondence should be addressed to M. Marton; marian.marton@stuba.sk
}

Received 28 June 2012; Revised 22 October 2012; Accepted 23 October 2012

Academic Editor: Roberto Flammini

Copyright (C) 2013 M. Marton et al. This is an open access article distributed under the Creative Commons Attribution License, which permits unrestricted use, distribution, and reproduction in any medium, provided the original work is properly cited.

\begin{abstract}
To meet various application requirements, it is important to enable an improvement of a-C structure and properties, such as hardness, adhesion, and wear resistance. In this study, we used the Raman spectroscopy to investigate the a-C thin films structure dependence on the different deposition parameters. The effect of nitrogen, argon, and hydrogen gas flow rate was analyzed to determine the influence on the film properties. The change in the gas type, combination, and flow had a significant influence on the $\mathrm{D}$ and $\mathrm{G}$ bands of the a-C Raman spectra. The addition of $\mathrm{N}_{2}$ into the chamber promoted the $\mathrm{sp}^{2}$ creation, while with adding hydrogen the layer contained more $\mathrm{sp}^{3}$ bonds. The depositions of a-C thin films were carried out in pulsed arc discharge vacuum installation. Micro-Raman measurements of the deposited materials were performed using an ISA Dilor-Jobin Yvon-Spex Labram confocal system with $632.8 \mathrm{~nm}$ radiation from a He-Ne laser using a back-scattering geometry.
\end{abstract}

\section{Introduction}

In recent years, a lot of work has been focused on the synthesis of novel carbon thin films materials, especially crystalline diamond, amorphous carbon (a-C), and carbon nitride (aC:N) which offers excellent tribological, optical, electrical, and other properties with the additional advantage that carbon is a biocompatible material. The huge range of properties achievable in carbon coatings is mainly due to the ability of carbon to form different types of interatomic bonds, to take up different sites, and to adopt different structures. However, for each application, there are different requirements on the film properties, for example, the adhesion level achievable and coating cost. Therefore, several methods to influence the a-C films structure, composition, and thus the properties, such as variation of ion energy, plasma treatment, pressure, and the use of different gases were presented [1-6].

Raman spectroscopy can be applied as a simple and accurate identification method of different carbon phases within the film. Due to its sensitivity to variation of translation symmetry, Raman spectroscopy allows distinguishing several types of carbon such as diamond, graphite, diamondlike carbon, and carbon nitride. The Raman spectra of nanocrystalline and amorphous carbon are dominated by the $D$ (D for disorder) and G (G for graphite) peaks with varied intensity, position, and band width [7-11]. The $G$ band at approximately $1540-1600 \mathrm{~cm}^{-1}$ corresponds to the symmetric $\mathrm{E}_{2 g}$ mode in graphite-like materials, while the D band at $1350 \mathrm{~cm}^{-1}$ arises from the limitations in the graphite domain size, induced by grain boundaries or imperfections, such as substitutional $\mathrm{N}$ atoms, $\mathrm{sp}^{3}$ carbon, or impurities. The D peak is not present in perfect single crystal graphite and becomes active only in the presence of disorder. For visible excitation, the $\mathrm{G}$ and $\mathrm{D}$ peaks are due to $\mathrm{sp}^{2}$ sites only. The $\mathrm{sp}^{2}$ sites have such a high cross-section that they dominate the spectra, the $\mathrm{sp}^{3}$ sites are invisible, and the spectrum responds only to the configuration or order of the $\mathrm{sp}^{2}$ sites. The Raman 


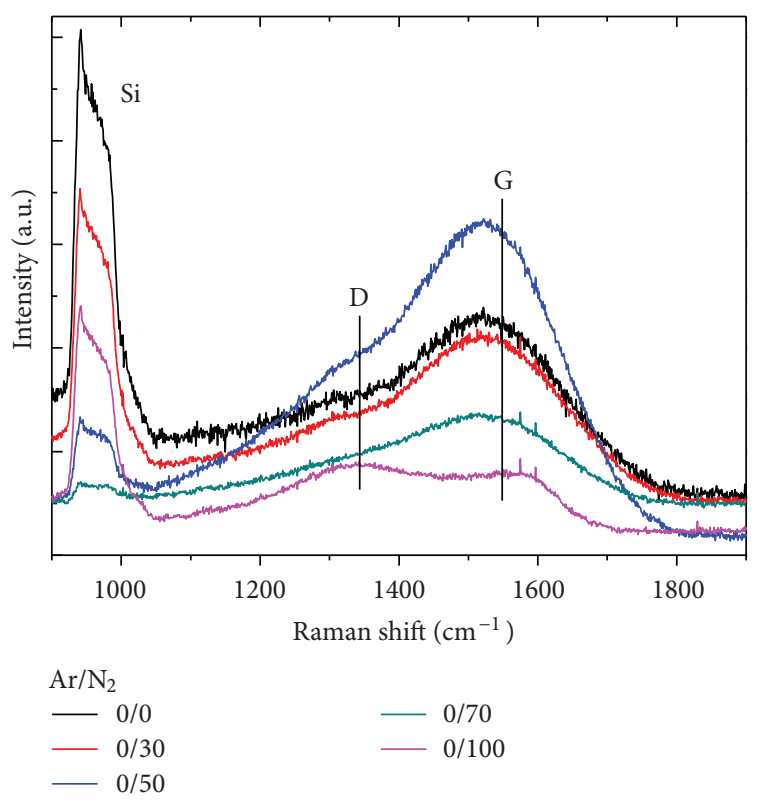

(a)
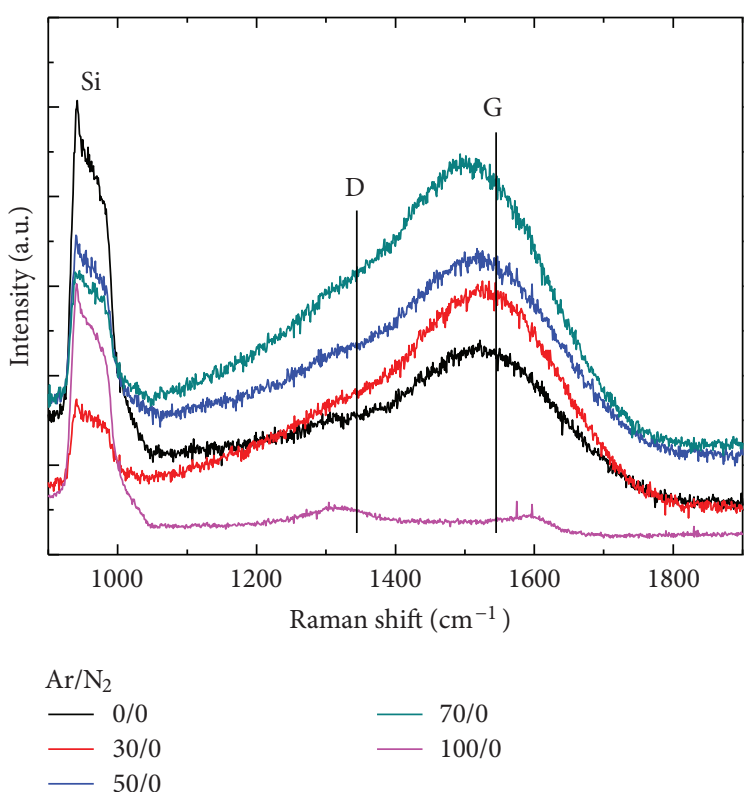

(b)

FIgURE 1: Raman spectra of a-C(:N) films deposited with various $\mathrm{N}_{2}$ (a) and $\mathrm{Ar}$ (b) flows.

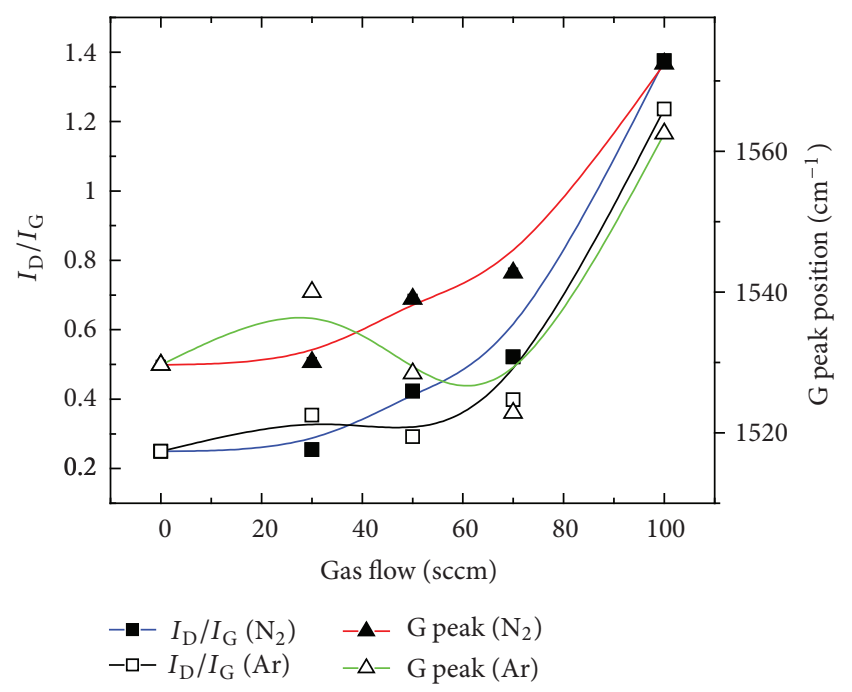

FIGURE 2: $I_{\mathrm{D}} / I_{\mathrm{G}}$ and $\mathrm{G}$ peak position dependence of the films deposited with various $\mathrm{N}_{2}$ and Ar flows.

spectra of a-C depend on (1) clustering of the $\mathrm{sp}^{2}$ phase; (2) bond length and bond angle disorder; (3) presence of $\mathrm{sp}^{2}$ rings or chains; (4) the $\mathrm{sp}^{2} / \mathrm{sp}^{3}$ ratio. The spectra directly depend on the quality or configuration of the $\mathrm{sp}^{2}$ phase and only indirectly on the quantity of the $\mathrm{sp}^{2}$ phase. Most times the $\mathrm{sp}^{2}$ configuration varies consistently with the $\mathrm{sp}^{2}$ fraction. However, in some cases, the $\mathrm{sp}^{2}$ quality can be changed independently from the $\mathrm{sp}^{2} / \mathrm{sp}^{3}$ ratio [12-17]. A weak peak at $2200 \mathrm{~cm}^{-1}$ is attributed to triple $\mathrm{C}-\mathrm{N}$ bonds and appears in the case of high nitrogen doping. The second-order silicon peak which appeared at $960 \mathrm{~cm}^{-1}$ can be used to measure the transparency of the film. The $I_{\mathrm{Si}} / I_{\mathrm{G}}$ ratio increases with the increase of $\mathrm{N}$ content in the film, revealing a reduction in the optical band gap when more $\mathrm{N}$ atoms are incorporated in films [18]. In this study, we used the Raman spectroscopy to investigate $\mathrm{a}-\mathrm{C}$ thin films structure and its dependence on the gas type and flow.

\section{Experimental}

The depositions of amorphous carbon thin films were carried out in a vacuum installation type UVNIPA-1-001 described previously [19]. The sputtering frequency of the arc source pulses was $5 \mathrm{~Hz}$. Background pressure was $10^{-4} \mathrm{~Pa}$ and working pressure was maintained around $1 \mathrm{~Pa}$ according to gas flow. Argon and nitrogen gas flow was varied from 0 to $100 \mathrm{sccm}$ and the flow of hydrogen from 20 to $60 \mathrm{sccm}$. The deposition temperature was kept below $100^{\circ} \mathrm{C}$. Mirror polished silicon substrates were used for deposition of the coatings. Before deposition of the layer, substrates were cleaned for $10 \mathrm{~min}$ with Ar ions within one vacuum cycle. The effects of nitrogen, argon, and hydrogen gas flow on the film properties were investigated by Raman spectroscopy. Micro-Raman measurements of the deposited materials were performed using an ISA Dilor-Jobin Yvon-Spex Labram confocal system with $632.8 \mathrm{~nm}$ radiation from a He-Ne laser using a back-scattering geometry. Microscope objective $\times 80$ was used to focus the laser beam onto a spot of approximately 1-5 $\mu \mathrm{m}$ in diameter and to collect the scattered light, which then passed through the spectrometer onto a CCD detector. The acquired Raman spectra were fitted with a Gaussian line to illustrate the $\mathrm{G}$ peak position and $I_{\mathrm{D}} / I_{\mathrm{G}}$ ratio. The XPS investigations were performed in an Omicron UHV system 

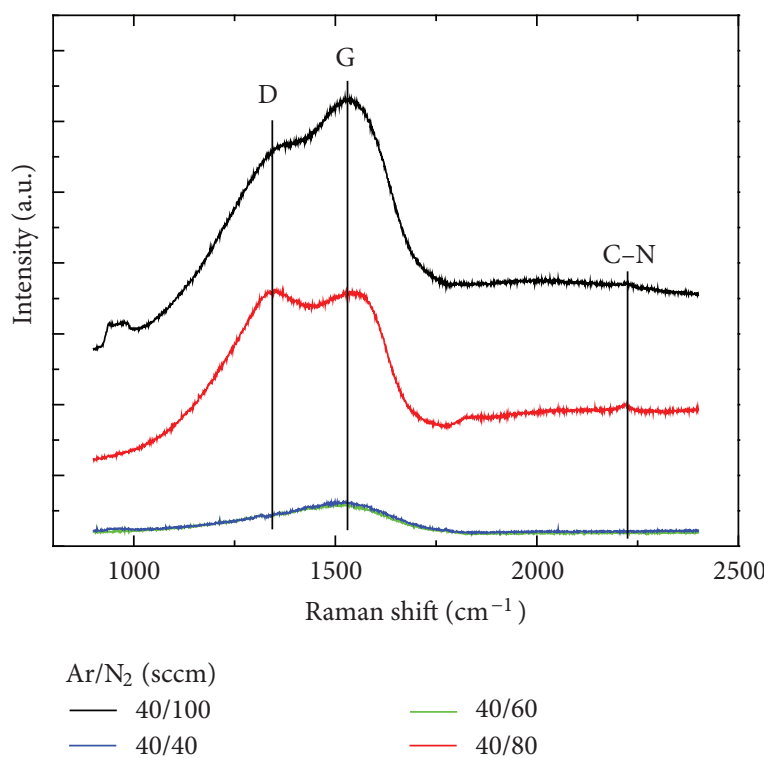

(a)

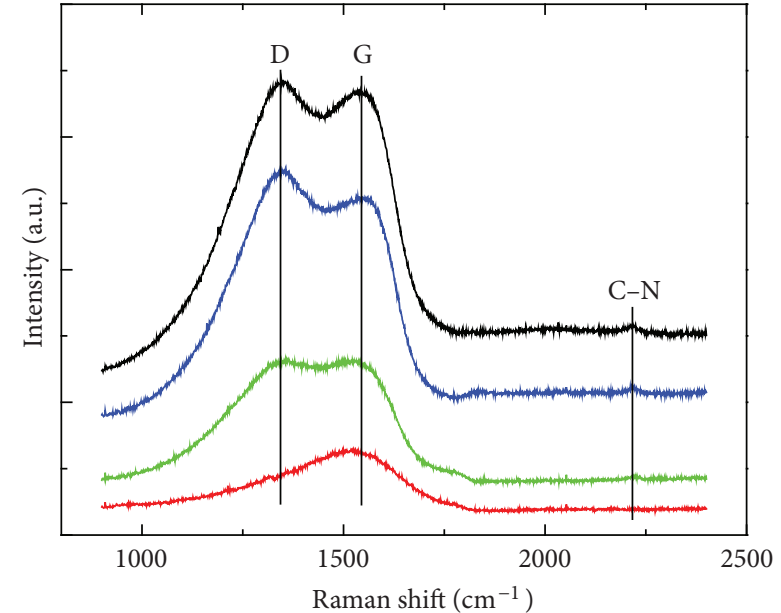

$\mathrm{Ar} / \mathrm{N}_{2}(\mathrm{sccm})$

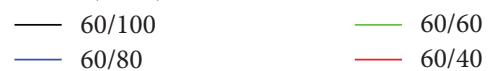

(b)

FIGURE 3: Raman spectra of a-C:N films deposited with constant $\mathrm{Ar}$ flow and various $\mathrm{N}_{2}$ flows.

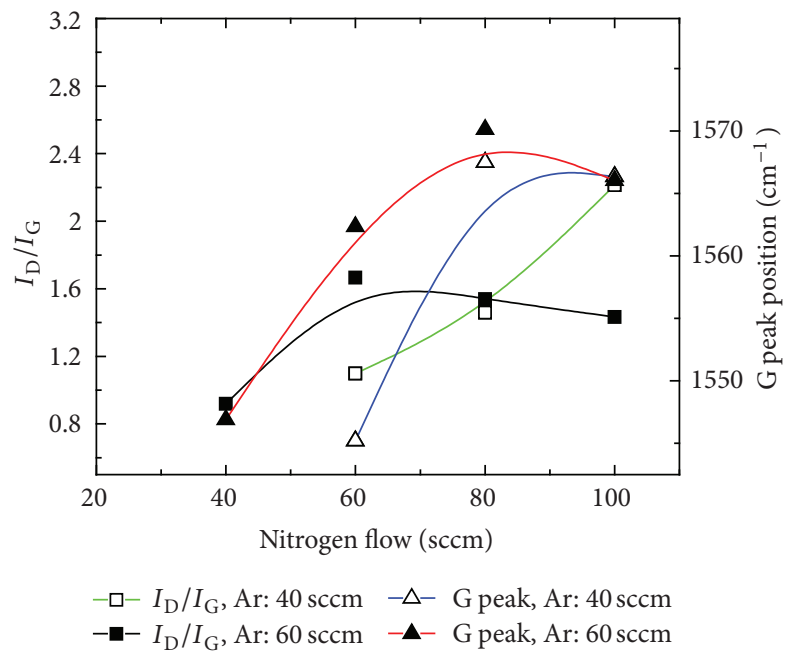

FIGURE 4: $I_{\mathrm{D}} / I_{\mathrm{G}}$ and $\mathrm{G}$ peak position dependence of the films deposited with constant Ar flow and various $\mathrm{N}_{2}$ flows.

equipped with an EA 125 hemispherical electron analyzer using monochromated AlK radiation (excitation energy $h=$ $1486.7 \mathrm{eV}$ ). The samples have been annealed by radiative heating from the backside at $500^{\circ} \mathrm{C}$ for $10 \mathrm{~min}$ in UHV conditions. The calibration of the energy scale was made by comparison to reference measurements on a polycrystalline silver sample and HOPG.

\section{Results and Discussion}

Raman spectra of the films deposited with various argon or nitrogen flow during the deposition process are shown in Figure 1. We can see that, with changing both $\mathrm{Ar}$ and $\mathrm{N}_{2}$ flow the intensity maximum of all three depicted bands ( $\mathrm{Si}$, $D, G$ band) changes significantly. The maximum intensity in Si band falls with increasing the process gas flow from 0 to $100 \mathrm{sccm}$. This indicates lowered transparency of the films due to the growth of a thicker layer and also due to more graphitic character of the films deposited with higher Ar or $\mathrm{N}_{2}$ flow [18]. Figure 2 shows the $I_{\mathrm{D}} / I_{\mathrm{G}}$ ratio and $\mathrm{G}$ peak position dependence of the films from Figure 1. For the layers deposited in nitrogen atmosphere both $I_{\mathrm{D}} / I_{\mathrm{G}}$ and $\mathrm{G}$ peak position increases as the amount of $\mathrm{N}_{2}$ in the chamber during deposition rises. The $I_{\mathrm{D}} / I_{\mathrm{G}}$ ratio is 0.25 for pure a-C film and 1.35 for film deposited with $100 \mathrm{sccm}$ of $\mathrm{N}_{2}$ flow. The G peak position rises from $1518 \mathrm{~cm}^{-1}$ for a-C to $1574 \mathrm{~cm}^{-1}$ for a-C:N with $100 \mathrm{sccm}$ of nitrogen flow. The simultaneous growth of both $I_{\mathrm{D}} / I_{\mathrm{G}}$ ratio and $\mathrm{G}$ peak position with increasing of nitrogen flow is a reliable indicator of $\mathrm{sp}^{3} / \mathrm{sp}^{2}$ ratio decrease and corresponds to another research [20]. From the spectra, we can assume that, nitrogen creates rather $\mathrm{sp}^{2}$ than $\mathrm{sp}^{3}$ bonds and the films become more graphitic when the $\mathrm{N}_{2}$ flow rises, which is similar to other studies $[11,14,18]$.

The $I_{\mathrm{D}} / I_{\mathrm{G}}$ ratio and $\mathrm{G}$ peak position of the films deposited with various Ar flow shows slight grow from 0 to $30 \mathrm{sccm}$, drop around $60 \mathrm{sccm}$ and sharp increase for films deposited in atmosphere with $100 \mathrm{sccm}$ of Ar flow. The films around $60 \mathrm{sccm}$ Ar flow have the lowest $I_{\mathrm{D}} / I_{\mathrm{G}}$ ratio and it seems such a moderate Ar flow is optimal for deposition of the films with higher $\mathrm{sp}^{3} / \mathrm{sp}^{2}$ ratio. Further increasing of $\mathrm{Ar}$ flow caused more graphitic bonds within the films.

Raman spectra of the a-C:N films deposited with combined $\mathrm{Ar} / \mathrm{N}_{2}$ flow are shown in Figure 3. The Ar flow was set constant to the values with best results from previous depositions (40 and $60 \mathrm{sccm}$ ) while the $\mathrm{N}_{2}$ flow was changed from 40 to $100 \mathrm{sccm}$ to estimate the influence of nitrogen in the combined gas flow. From $I_{\mathrm{D}} / I_{\mathrm{G}}$ ratio and $\mathrm{G}$ peak 

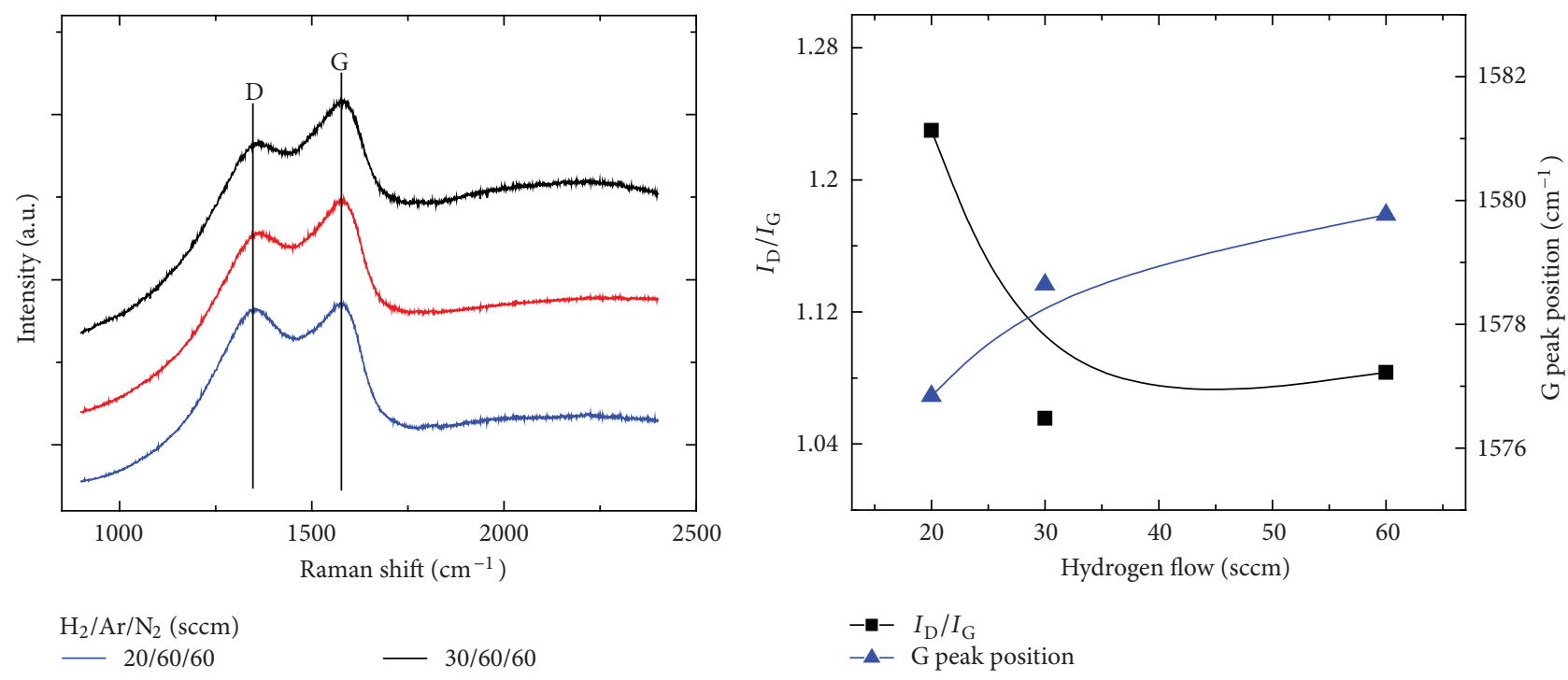

(a)

(b)

Figure 5: Raman spectra of a-C:N:H grown with constant $\mathrm{Ar} / \mathrm{N}_{2}$ flow (a), $I_{\mathrm{D}} / I_{\mathrm{G}}$ and $\mathrm{G}$ peak position dependence of the films (b).

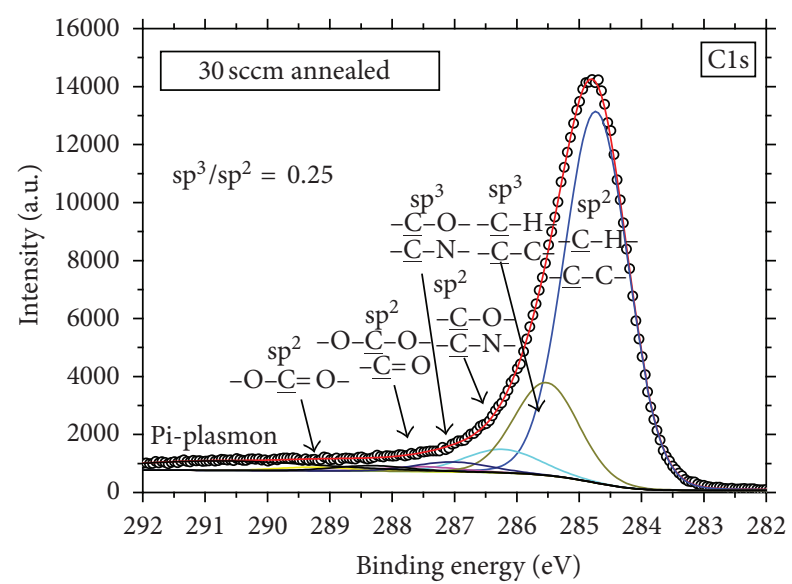

(a)

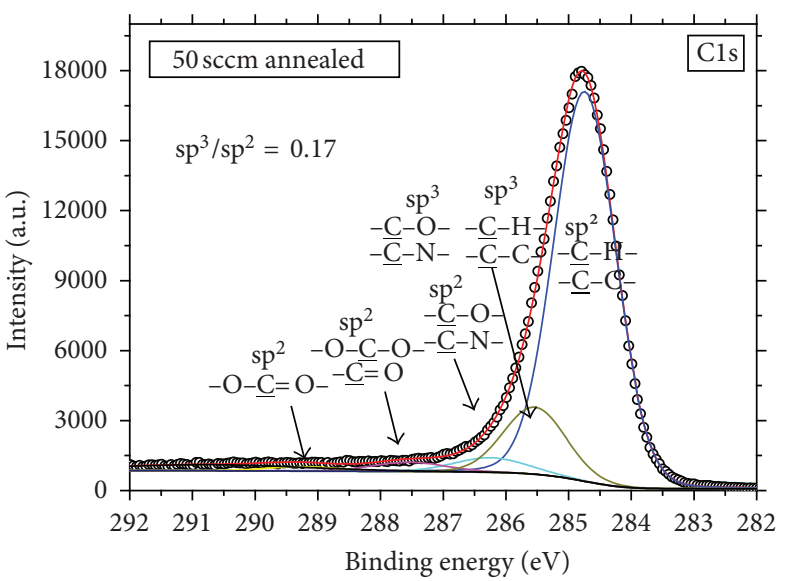

(b)

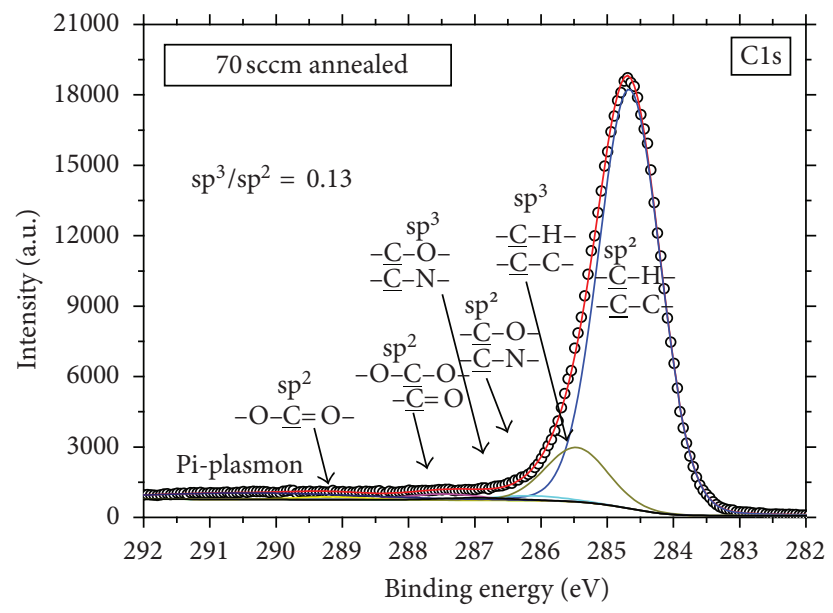

(c)

FIGURE 6: The XPS spectra of the a-C:N films deposited with 30, 50, and $70 \mathrm{sccm}$ of $\mathrm{N}_{2}$. 
position dependence shown in the Figure 4 it is obvious that, for the films deposited with 40 and $60 \mathrm{sccm}$ argon flows, the maximum of $\mathrm{G}$ peak position is around 80 and $60 \mathrm{sccm}$ of nitrogen flow, respectively. The values of $I_{\mathrm{D}} / I_{\mathrm{G}}$ ratio and $\mathrm{G}$ peak position for all gas combined depositions are higher than for layers deposited with only one gas type. Therefore, we can assume that, the further $\mathrm{Ar} / \mathrm{N}_{2}$ admixture into the chamber during deposition process promotes the creation of $\mathrm{sp}^{2}$ bonding in the thin film. Besides the main D and G broad peaks, with increasing the $\mathrm{N}_{2}$ flow we can observe also a small local maximum at approximately $2200 \mathrm{~cm}^{-1}$ attributed to triple $\mathrm{C}-\mathrm{N}$ bonds. This band is characteristic with very small intensity in the Raman spectra made using visible laser excitation [21,22].

Figure 5 shows the Raman spectra and data abstracted from fitting of the films deposited with constant $\mathrm{Ar} / \mathrm{N}_{2}$ flow while adding $\mathrm{H}_{2}$ into the gas mixture. As we can see, the $I_{\mathrm{D}} / I_{\mathrm{G}}$ ratio decreased from 1.6 for nonhydrogenated a-C:N to 1.1 due to the presence of hydrogen in the gas mixture. The $\mathrm{G}$ peak position is changing only slightly towards higher values. The creation of $\mathrm{sp}^{2}$ phase is due to the hydrogen addition lower. This may be due to hydrogen affecting as an etchant of graphitic bonds during growth of the film causing the higher $\mathrm{sp}^{3}$ content.

For comparison, XPS analysis of the a-C:N samples deposited with 30,50 , and $70 \mathrm{sccm}$ of $\mathrm{N}_{2}$ flow was made (Figure 6). The resulting $\mathrm{sp}^{3} / \mathrm{sp}^{2}$ ratio decreased with nitrogen flow increasing. The results correspond to the Raman measurements made on these samples and are in agreement with other studies $[13,15,18]$.

\section{Conclusions}

We deposited continuous, homogeneous, and adhesive a-C, a-C:N and a-C:N:H thin films on Si substrates using pulsed vacuum arc discharge technique. Following the Raman spectra we found that, with adding different gases with various concentrations the film structure and properties change significantly. The addition of $\mathrm{N}_{2}$ and/or Ar caused the simultaneous growth of both $I_{\mathrm{D}} / I_{\mathrm{G}}$ ratio and $\mathrm{G}$ peak position which is a reliable indicator of $\mathrm{sp}^{3} / \mathrm{sp}^{2}$ ratio decrease and increase of graphitic contents in the films. The films with only a moderate Ar flow had lower $I_{\mathrm{D}} / I_{\mathrm{G}}$ ratio and this was found to be optimal for deposition of the films with high $\mathrm{sp}^{3} / \mathrm{sp}^{2}$ ratio. The addition of hydrogen into the gas mixture caused the decrease in $I_{\mathrm{D}} / I_{\mathrm{G}}$ ratio and thus we can expect lower amount of graphitic $\mathrm{sp}^{2}$ bonding. We found that, the maximum intensity of Si band falls with increasing of the process gas flow. This indicates lowered transparency of the films due to the growth of a thicker layer and also due to the more graphitic character of films deposited with higher $\mathrm{Ar}$ and/or $\mathrm{N}_{2}$ flow.

\section{Acknowledgments}

This work was done in Center of Excellence CENAMOST (Slovak Research and Development Agency Contract no.
VVCE-0049-07) and was financially supported also by Grants APVV-0548-07, LPP-0149-09, DAAD 507552 00, and VEGA $1 / 1103 / 11,1 / 1102 / 11,1 / 0264 / 11$.

\section{References}

[1] J. Robertson, "Diamond-like amorphous carbon," Materials Science and Engineering R, vol. 37, no. 4-6, pp. 129-281, 2002.

[2] W. Ensinger, "Correlations between process parameters and film properties of diamond-like carbon films formed by hydrocarbon plasma immersion ion implantation," Surface and Coatings Technology, vol. 203, no. 17-18, pp. 2721-2726, 2009.

[3] S. Neuville and A. Matthews, "A perspective on the optimisation of hard carbon and related coatings for engineering applications," Thin Solid Films, vol. 515, no. 17, pp. 6619-6653, 2007.

[4] G. A. Viana, E. F. Motta, M. E. H. M. da Costa, F. L. Freire Jr., and F. C. Marques, "Diamond-like carbon deposited by plasma technique as a function of methane flow rate," Diamond and Related Materials, vol. 19, no. 7-9, pp. 756-759, 2010.

[5] H. Ma, L. Zhang, N. Yao, B. Zhang, H. Hu, and G. Wen, “The effect of nitrogen addition on field emission of diamond-like carbon films," Diamond and Related Materials, vol. 9, no. 9-10, pp. 1608-1611, 2000.

[6] S. Da-Cheng, L. Yi-Chun, L. Yan, Q. Xiu-Ying, and Z. DianQiang, "Structural and electrical properties of amorphous hydrogen carbon-nitrogen films," Chinese Physics Letters, vol. 21, no. 2, article 400, 2004.

[7] A. C. Ferrari and J. Robertson, "Interpretation of Raman spectra of disordered and amorphous carbon," Physical Review B, vol. 61, no. 20, pp. 14095-14107, 2000.

[8] A. C. Ferrari, "Determination of bonding in diamond-like carbon by Raman spectroscopy," Diamond and Related Materials, vol. 11, no. 3-6, pp. 1053-1061, 2002.

[9] J. Filik, P. W. May, S. R. J. Pearce, R. K. Wild, and K. R. Hallam, "XPS and laser Raman analysis of hydrogenated amorphous carbon films," Diamond and Related Materials, vol. 12, no. 3-7, pp. 974-978, 2003.

[10] J. R. Shi, Y. J. Xu, and J. Zhang, "Study on amorphous carbon nitride film prepared by facing target sputtering," Thin Solid Films, vol. 483, no. 1-2, pp. 169-174, 2005.

[11] L. Valentini, J. M. Kenny, Y. Gerbig et al., "Structure and mechanical properties of argon assisted carbon nitride films," Thin Solid Films, vol. 398-399, pp. 124-129, 2001.

[12] J. Li, W. T. Zheng, Z. Jin et al., "Influence of substrate dc bias on chemical bonding, adhesion and roughness of carbon nitride films," Applied Surface Science, vol. 191, no. 1-4, pp. 273-279, 2002.

[13] J. R. Shi, X. Shi, Z. Sun, S. P. Lau, B. K. Tay, and H. S. Tan, "Resonant Raman studies of tetrahedral amorphous carbon films," Diamond and Related Materials, vol. 10, no. 1, pp. 76-81, 2001.

[14] V. Kopustinskas, S. Meskinis, V. Grigaliunas et al., "Ion beam synthesis of $\alpha-\mathrm{CN}_{\mathrm{x}}: \mathrm{H}$ films," Surface and Coatings Technology, vol. 151-152, pp. 180-183, 2002.

[15] R. Hauert, A. Glisenti, S. Metin et al., "Influence of nitrogen doping on different properties of a-C:H," Thin Solid Films, vol. 268, no. 1-2, pp. 22-29, 1995.

[16] S. C. H. Kwok, P. Yang, J. Wang, X. Liu, and P. K. $\mathrm{Chu}$, "Hemocompatibility of nitrogen-doped, hydrogen-free diamond-like carbon prepared by nitrogen plasma immersion 
ion implantation-deposition," Journal of Biomedical Materials Research A, vol. 70, no. 1, pp. 107-114, 2004.

[17] L. Y. Chen, C.-Y. Cheng, and F. C. Hong, "Properties of carbon nitride $\left(\mathrm{CN}_{\mathrm{x}}\right)$ films deposited by a high-density plasma ion plating method," Diamond and Related Materials, vol. 11, pp. 1172-1177, 2002.

[18] S. S. Roy, S. S. Roy, R. McCann, P. Papakonstantinou, P. Maguire, and J. A. McLaughlin, "The structure of amorphous carbon nitride films using a combined study of NEXAFS, XPS and Raman spectroscopies," Thin Solid Films, vol. 482, no. 1-2, pp. 145-150, 2005.

[19] M. Marton, E. Zdraveckáb, M. Vojs et al., "Study of adhesion of carbon nitride thin films on medical alloy substrates," Vacuum, vol. 84, no. 1, pp. 65-67, 2010.

[20] J. H. Sui, Z. Y. Gao, W. Cai, and Z. G. Zhang, "DLC films fabricated by plasma immersion ion implantation and deposition on the NiTi alloys for improving their corrosion resistance and biocompatibility," Materials Science and Engineering A, vol. 454455, pp. 472-476, 2007.

[21] N. A. Morrison, S. E. Rodil, J. Robertson, and W. I. Milne, "Chemical sputtering of ta-C: implications for the deposition of carbon nitride," Journal of Applied Physics, vol. 89, no. 10, pp. 5754-5759, 2001.

[22] A. C. Ferrari, S. E. Rodil, and J. Robertson, "Resonant Raman spectra of amorphous carbon nitrides: the G peak dispersion," Diamond and Related Materials, vol. 12, no. 3-7, pp. 905-910, 2003. 

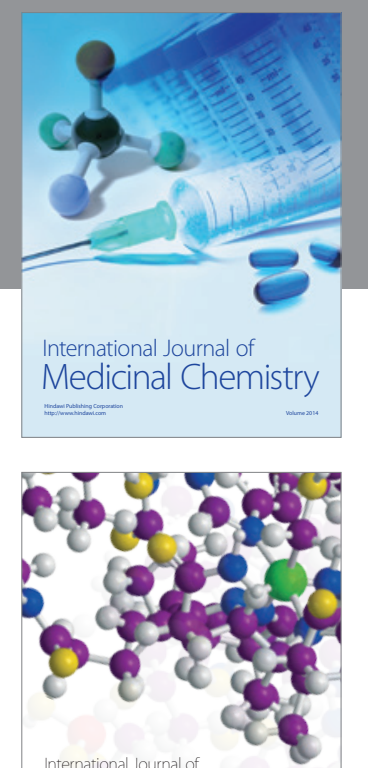

\section{Carbohydrate} Chemistry

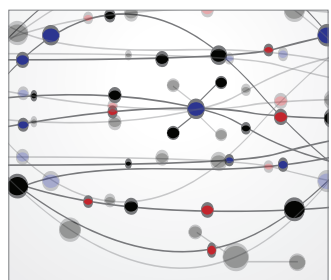

The Scientific World Journal
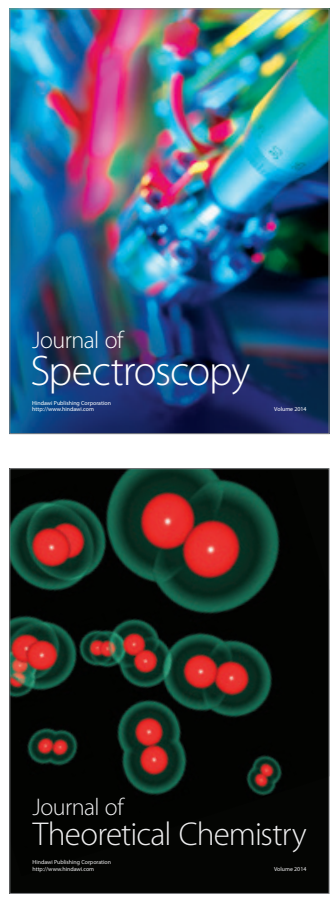
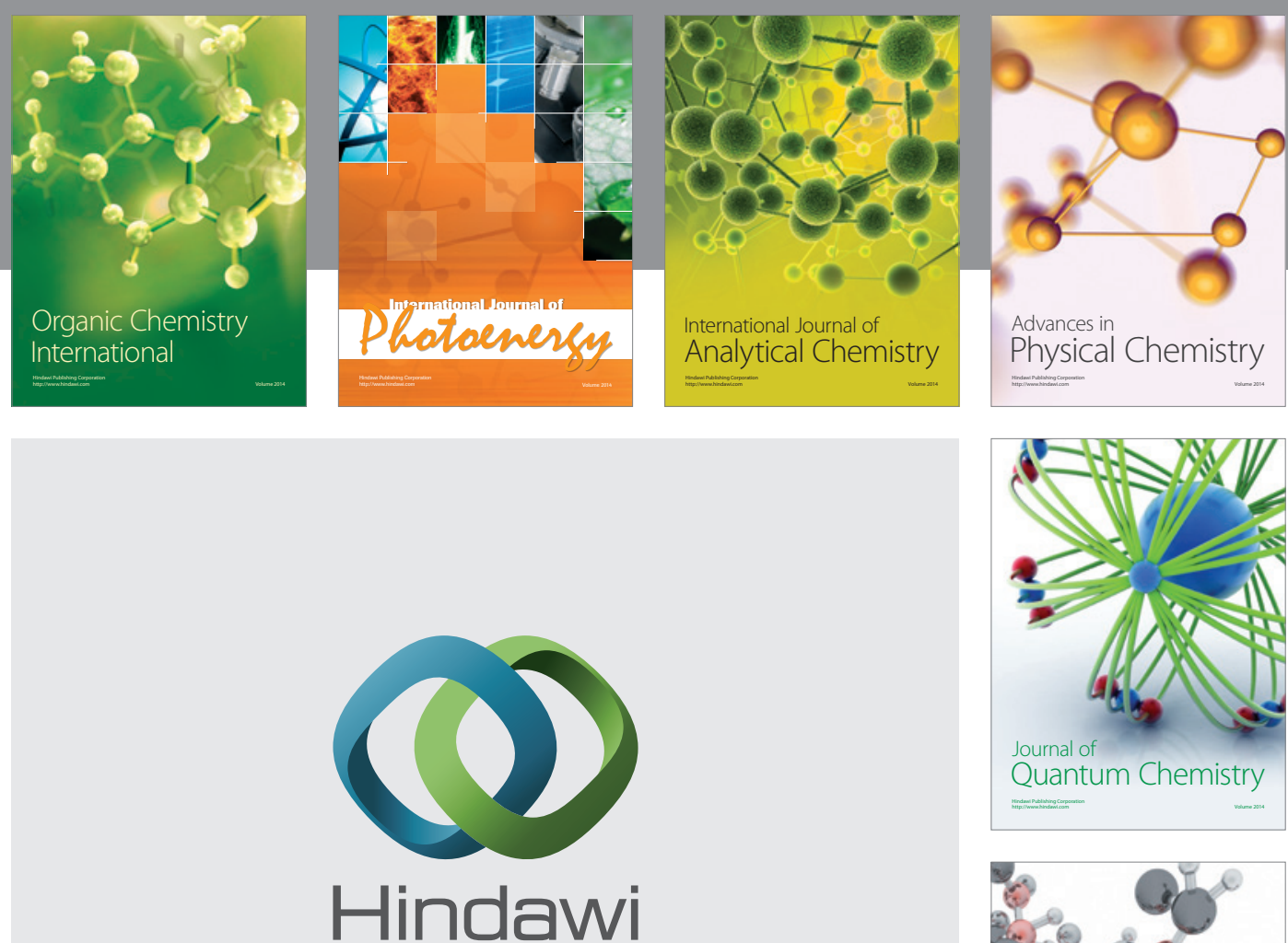

Submit your manuscripts at

http://www.hindawi.com

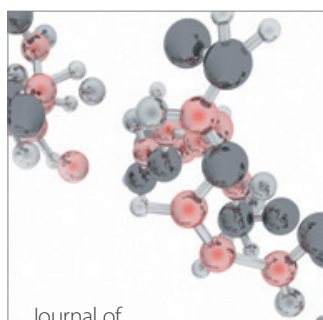

Analytical Methods

in Chemistry

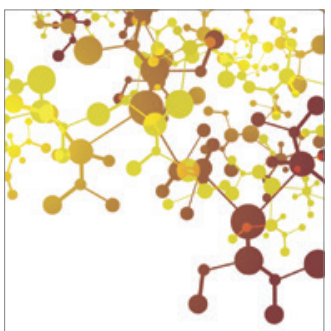

Journal of

Applied Chemistry

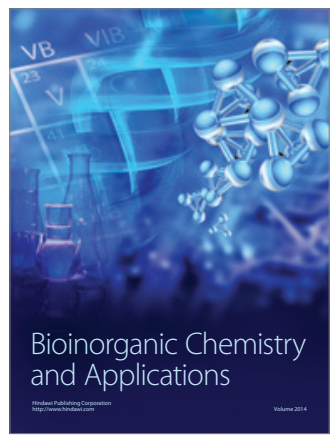

Inorganic Chemistry
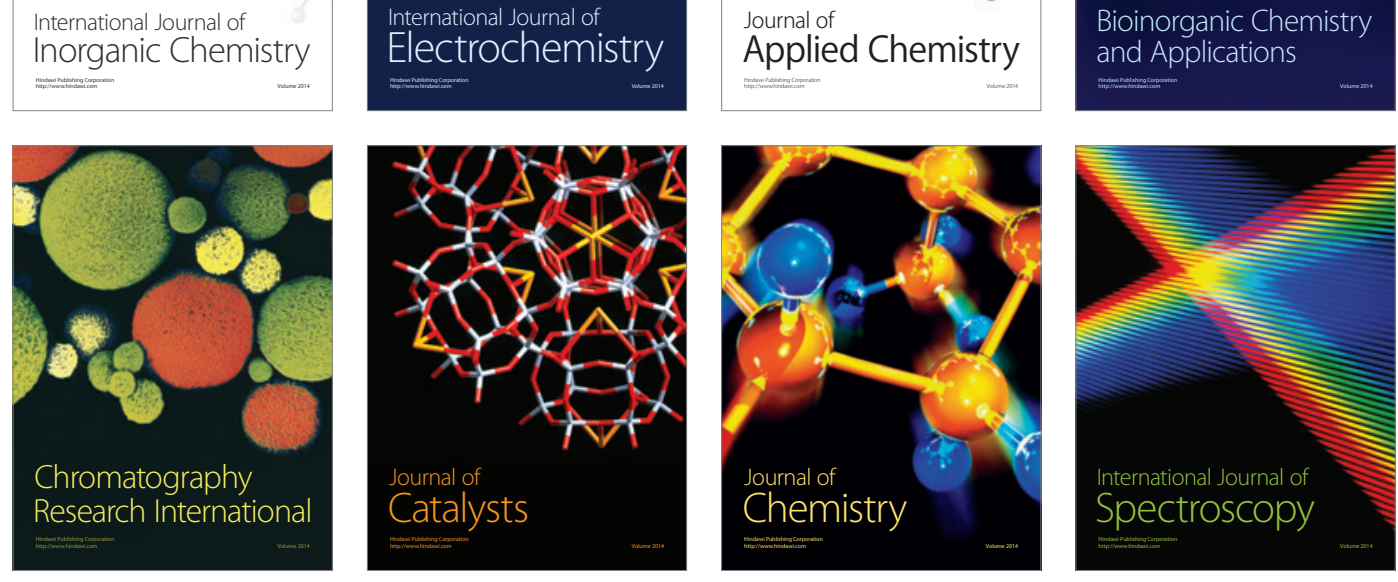